\title{
Optimized Rhodium Dissolution Process Using Aqua Regia
}

\author{
Tejas Shyama,* (D), Akshay Ajita, Rakesh Jangida
}

a Precious Alloys Private Limited Company, Mumbai, India

\section{ART ICLE I N F O}

Received: 10 June 2019

Revised: 10 July 2019

Accepted: 20 August 2019

Available online: 21 August 2019

\section{K E Y W O R D S}

Rhodium dissolution Optimized

Aqua regia

\section{A B S T R A C T}

The present paper focuses on a unique, optimized process of completely dissolving rhodium that can be employed on a large scale. Dissolution of rhodium has always been a challenging aspect of rhodium metallurgy due to its poor solubility even in mineral acids under ordinary conditions. In this paper, we present a means of achieving complete dissolution of rhodium powder in aqua regia using an experimentally optimized set of process parameters including solvent volume, temperature and heating time. The result is a solution in which the rhodium is completely dissolved which is confirmed by using optical microscopy at 50x magnification. Further, through the outcome of the experiments, it is concluded that it is possible to qualitatively ascertain the extent of rhodium content in the powder by observing the color of the solution. Comparison is also carried out with results obtained from dissolution experiments employing non-optimized process parameters in aqua regia as solvent.

GRA P H I C A L A B S T RACT

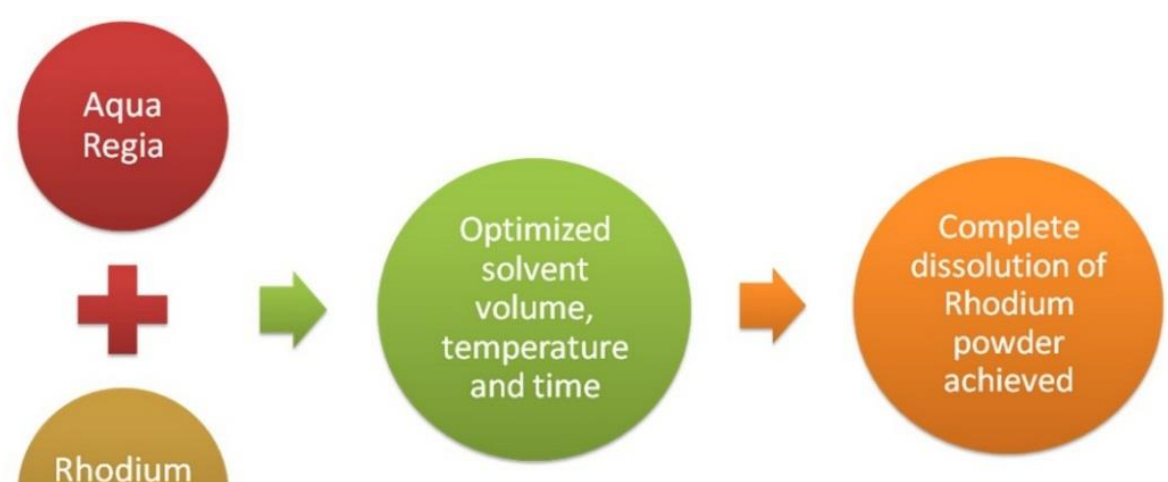

Rowder

* Corresponding author's E-mail address: tejasumashyam@gmail.com 


\section{Introduction}

Rhodium is one of the rarest elements in the earth's crust [1]. A metal, it has widespread practical use. The use of rhodium phosphate for very white and reflective deposits, rhodium sulfate for general jewelry and industrial deposits and mixed phosphate- sulfate for general decorative deposits is widely known [2].

However, the dissolution of rhodium presents many challenges such as low dissolution efficiency, high reagent consumption and complex operation [3]. It is one of the most difficult materials to dissolve in aqueous solutions [4]. Rhodium is poorly soluble in mineral acids or their mixtures under normal conditions [5].

Many chemical methods have been proposed to dissolve rhodium containing alloys. These include using a mix of $\mathrm{HNO}_{3}, \mathrm{HCl}$ and $\mathrm{HF}$ for $\mathrm{Rh}(1 \%) / \mathrm{SiO}_{2}$ catalyst [6], a mixture of $\mathrm{H}_{2} \mathrm{SO}_{4}$ and $\mathrm{HNO}_{3}$ for $\mathrm{RhI}_{3}$ catalyst [7] and $\mathrm{KBF}_{4}$ for Pt$\mathrm{Rh}(0.5 \%$ by mass) alloy [8]. However, in all the methods, high concentration of rhodium cannot be dissolved easily.

There is, therefore, a definite need to improve dissolution efficiency of rhodium, especially if it is in high concentration, if it has to be used for industrial applications, especially for plating applications where the plating bath needs a relatively high dissolved rhodium content at all times in order to create effective platings.

To address this issue, we have created a method of completely dissolving rhodium from powder obtained by precipitation of solution including rhodium and at least copper and/or gold, which can be used for large scale rhodium dissolution, using aqua regia (a mixture of 3:1 solutions of $\mathrm{HCl}: \mathrm{HNO}_{3}$ ) under high temperature and high pressure using an experimentally optimized set of process parameters.

\section{Experimental}

For dissolving rhodium, we used rhodium powder obtained by precipitation from a solution containing rhodium and at least one other metal from among copper and gold. Aqua regia was used as the solvent. A polymer container with a lid specially designed to withstand high pressure and temperature without any leakage or cracking, along with a stainless steel (SS) reactor vessel, was also used to contain the solution during the heating process. For heating, a Static Furnace was used.

To analyze the solution of the sample post dissolution, we used the Perkin Elmer Optima Series Inductively Coupled Plasma (ICP) Spectroscopy machine. The optical microscope used for analysis was the Dino-Lite Digital Microscope and the images were captured via USB output using the Dino-Capture computer software.

All mass measurements were made using a digital weighing scale having a precision of 1 microgram. All volumes were transferred using a pipette.

$50 \mathrm{mg}$ of sample powder was weighed (with an accuracy of $0.01 \%$ ) in the polymer container. Thereafter, $4 \mathrm{~mL}$ of freshly prepared aqua regia (containing $3 \mathrm{~mL} \mathrm{HCl} \& 1 \mathrm{~mL} \mathrm{HNO}_{3}$ ) was added to the container and the container was capped with its lid. Finally, this container was placed in the SS reactor vessel and due care was taken to ensure that all the lids were shut tightly to prevent any possibility of solvent and/or power evaporation during processing. The SS reactor vessel was kept in the heating furnace for 24 hours at $220^{\circ} \mathrm{C}$.

After the stipulated time, the heating was turned off and the reactor was furnace cooled to room temperature. Thereafter, the reactor and container were opened. The solution was observed in a clean, white plastic container using an optical microscope at 50x magnification and further analyzed by using the ICP Spectroscopy Machine.

The above experimental procedure was repeated with different samples of rhodium powder containing varying percentages of rhodium, in order to check whether the amount of rhodium present in the powder sample has 
any impact on the process parameters.

Table 1. Summary of process parameters used in comparative experiments

\begin{tabular}{ccccc} 
Solvent used & Powder Mass & Solvent Volume & Heating Time & $\begin{array}{c}\text { Heating } \\
\text { Temperature }\end{array}$ \\
\hline Aqua Regia & $50 \mathrm{mg}$ & $4 \mathrm{~mL}$ solvent & 4 hours & $200{ }^{\circ} \mathrm{C}$ \\
Aqua Regia & $50 \mathrm{mg}$ & $4 \mathrm{~mL}$ solvent & 8 hours & $200{ }^{\circ} \mathrm{C}$ \\
Aqua Regia & $50 \mathrm{mg}$ & $4 \mathrm{~mL}$ solvent & 10 hours & $200{ }^{\circ} \mathrm{C}$ \\
Aqua Regia & $50 \mathrm{mg}$ & $4 \mathrm{~mL}$ solvent & 16 hours & $20{ }^{\circ} \mathrm{C}$ \\
Aqua Regia & $50 \mathrm{mg}$ & $4 \mathrm{~mL}$ solvent & 24 hours & $150{ }^{\circ} \mathrm{C}$ \\
Aqua Regia & $50 \mathrm{mg}$ & $4 \mathrm{~mL}$ solvent & 24 hours & $180{ }^{\circ} \mathrm{C}$ \\
Aqua Regia & $50 \mathrm{mg}$ & $4 \mathrm{~mL}$ solvent & 24 hours & $200^{\circ} \mathrm{C}$ \\
\hline
\end{tabular}

Figure 1. Color of the various solutions containing rhodium in differing percentages

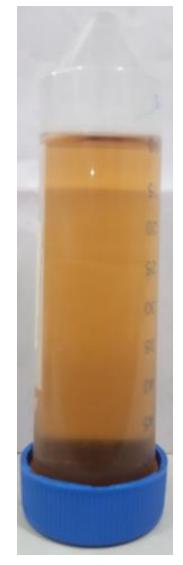

(a) $50.70 \% \mathrm{Rh}$

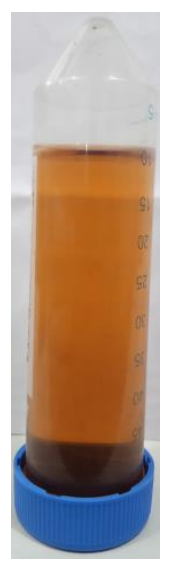

(b) $99.59 \% \mathrm{Rh}$

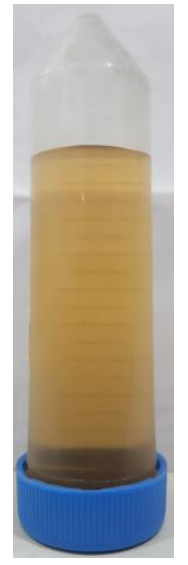

(c) $34.56 \% \mathrm{Rh}$
The above experimental procedure was obtained after a lot of other experimental trials were conducted using varying process parameters with aqua regia as solvent. These experiments were an attempt to optimize the dissolution process. Table 1 provides a summary of the process parameters. In all the cases, the mass of sample powder and solvent volume were used as control variables. The results of these experiments have been further discussed in the following section on results and discussion.

\section{Results and Discussion}

The solutions obtained as a result of repeated experiments with different $50 \mathrm{mg}$ powder samples in $4 \mathrm{~mL}$ aqua regia with a heating temperature of $220^{\circ} \mathrm{C}$ and heating time of 24 hours were optically clear and displayed a range of color, from goldenyellow to deep red, as shown in Figure 1.

ICP spectroscopy measurement and analysis of these solutions revealed that the percentage of rhodium in the solution could be correlated to its color. As can be seen in Figure 1, the powder sample containing a higher percentage of rhodium gives a redder color solution upon dissolution in aqua regia. The lower the rhodium percentage, the yellower the color 
of the solution obtained upon dissolution.

The above result creates a scope for the further development of a method of qualitative comparison of the relative rhodium content in various solutions through simple visual inspection. This idea can further be explored through more research, and it is worthwhile to do so since industrial users will find it very convenient and easy to use an optical, qualitative analysis tool to gauge the approximate rhodium content in various plating solutions.

While there is no powder or precipitate visible to the naked eye in the solutions discussed above, the Optical Microscopy of these solutions at a magnification of $50 \mathrm{x}$ also showed no visible powder or precipitate. Figure 2 shows the image obtained for the $99.59 \% \mathrm{Rh}$ containing sample solution viewed under the optical microscope.

As can be seen in Figure 2 above, there is no powder residue seen under the microscope. Powder residue, if any, should have appeared as black particulates, since the original sample powder had black color. The absence of any black particulates in the image at $50 \mathrm{x}$ confirms the fact that complete rhodium dissolution has been achieved. The white spots seen in the image are the result of reflections of light when the clear solution is illuminated under the microscope, and do not indicate any powder residue. The reason the color of the solution in Figure 2 seems relatively dull compared to the solution seen in Figure 1 (c) is because a white plastic container was used to contain the solution for microscopy, which makes the otherwise deep red shade seem lighter.

Thus, it can be confidently concluded that the process parameters involving a heating temperature of $220{ }^{\circ} \mathrm{C}$ and heating time of 24 hours effectively enable the complete dissolution of rhodium powder in aqua regia.

The results of the other experiments performed using a variety process parameters using $4 \mathrm{~mL}$ aqua regia as solvent with $50 \mathrm{mg}$ of powder sample as summarized in Table 1 are given below in Table 2. As mentioned earlier, these experiments were an attempt to optimize the process parameters.

As can be seen from the Table 2, these results give unsatisfactory dissolution. Given that there is a visible black residue in all cases, the rhodium dissolution is definitely incomplete. Moreover, since the rhodium powder doesn't dissolve, it is not possible to draw any qualitative inference regarding the rhodium content in the powder from the color of the solution.

Figure 2. Optical microscopy image of $99.59 \%$ rhodium solution at magnification of $50 \mathrm{x}$

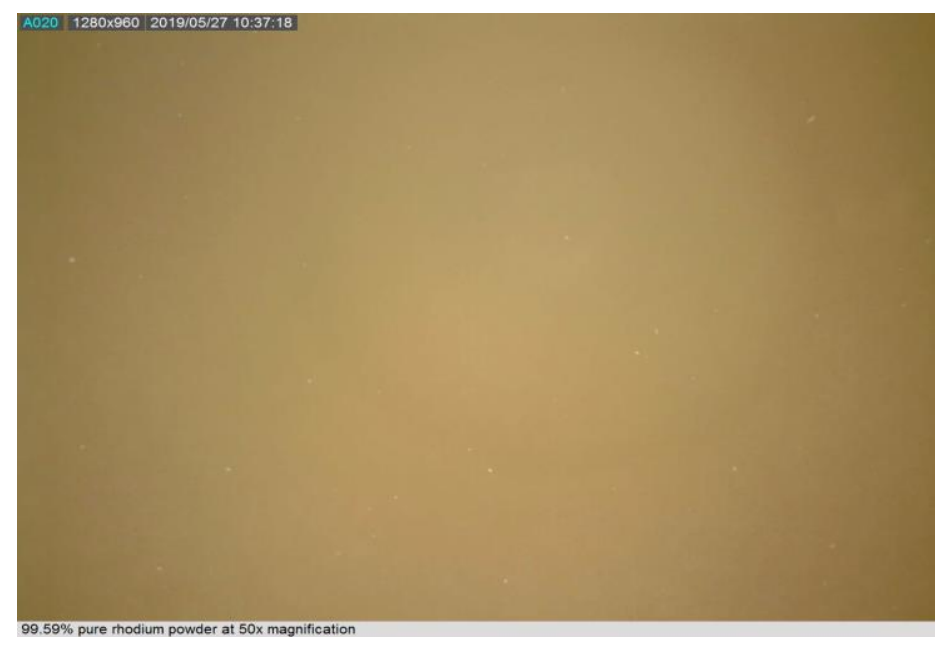


Table 2. Effect of various process parameters

\begin{tabular}{|c|c|c|}
\hline $\begin{array}{l}\text { Heating } \\
\text { Time }\end{array}$ & $\begin{array}{l}\text { Heating } \\
\text { Temperature }\end{array}$ & Observations \\
\hline 4 hours & $200{ }^{\circ} \mathrm{C}$ & No visible dissolution. Black powder at the bottom \\
\hline 8 hours & $200{ }^{\circ} \mathrm{C}$ & No visible dissolution. Black powder at the bottom \\
\hline 10 hours & $200{ }^{\circ} \mathrm{C}$ & No visible dissolution. Black powder at the bottom \\
\hline 16 hours & $200{ }^{\circ} \mathrm{C}$ & No visible dissolution. Black powder at the bottom \\
\hline 24 hours & $150{ }^{\circ} \mathrm{C}$ & No visible dissolution. Black powder at the bottom \\
\hline 24 hours & $180{ }^{\circ} \mathrm{C}$ & $\begin{array}{l}\text { Incomplete but definite visible dissolution, } \\
\text { confirmed using mass balance }\end{array}$ \\
\hline 24 hours & $200^{\circ} \mathrm{C}$ & $\begin{array}{l}\text { Almost complete dissolution, but still a little black } \\
\text { residue visible }\end{array}$ \\
\hline
\end{tabular}

Also, looking at the data in Table 2, it is clearly seen how the optimization was gradually achieved through experimentation. As the process parameters approach 24 hours of heating time and $220{ }^{\circ} \mathrm{C}$ heating temperature, the dissolution improves. This enabled us to successfully and iteratively experimentally optimize the process parameters.

\section{Conclusion}

Rhodium dissolution is a relatively challenging task, owing to its poor solubility even in strong mineral acids. However, using a heating time of 24 hours and temperature of $220{ }^{\circ} \mathrm{C}$, we have demonstrated in this paper that it is possible to achieve complete dissolution of rhodium powder in aqua regia.

While we have used $50 \mathrm{mg}$ of rhodium and $4 \mathrm{~mL}$ of aqua regia for experimentation, large scale dissolution of rhodium can be carried out using the same procedure by simply proportionately changing the volume of aqua regia depending on the mass of rhodium powder taken.

As seen in the previous section of this paper, it can also be concluded that the color of the aqua regia solution containing the dissolved powder is a qualitative indicator of the percentage of rhodium in the sample. This fact can be used to further develop a simple qualitative analytical tool that can be useful to the industry.

\section{Acknowledgment}

The authors would like to credit and thank Mr. Vicky Mahendru, CEO Precious Alloys Pvt. Ltd., for his wholehearted support, motivation and guidance.

\section{Disclosure statement}

No potential conflict of interest was reported by the authors.

\section{ORCID}

Tejas Shyam (D): 0000-0003-1182-9220

\section{References}

[1] F. Cardarelli, Materials Handbook: a Concise Desktop Reference, 2nd ed., Springer-Verlag, London, 1966, 411413.

[2] A.M. Weisberg, Metal Finishing,1999, 97, 297-301.

[3] H. Dong, W. Yunhua, L. Baiyu, F. 
Xingxiang, Chinese J, Rare Metal., 2011, 35, 939-944.

[4] Y. Kayanuma, T.H. Okabe, Y. Mitsuda, M. Maeda, J. Alloys Compd., 2004, 365, 211-220.

[5] Y. Danzaki, T. Ashino, Anal. Sci., 2001, 17, 1011-1013

[6] S. Recchi, G. Zanderighi, A. Fontana, C. Dossi, Ann. Chim-Rome, 1997, 87, 359-
366.

[7] I.A. Ryzhak, Z.I. Sukhareva, A.P. Zolotareva, B.M. Talalaev, Industrial Laboratory, 1982, 48, 792-793.

[8] V.N. Mit'kin, S.V. Zemskov, B.I. Zaksas, E.A. Petrova, A.N. Kurskii, J. Anal. Chem., USSR, 1991, 46, 1750-1756.

How to cite this manuscript: Tejas Shyam, Akshay Ajit, Rakesh Jangid. Optimized Rhodium Dissolution Process Using Aqua Regia. Adv. J. Chem. A, 2020, 3(2), 159-164. 